\title{
Desvario de comunicação possível para a biblioteca da pauliceia: a Mário de Andrade de Mário de Andrade
}

Rogério Pelizzari de Andrade

Jornalista e publicitário, especialista em Gestão da Comunicação pela Escola de Comunicações e Artes da Universidade de São Paulo, onde é mestrando em Ciências da Comunicação.

E-mail: rpelizzari@usp.br

Resumo: A Biblioteca Mário de Andrade é dona do segundo maior acervo do Brasil. Criada em 1926, viveu seu auge entre as décadas de 1940 e 1960. A partir daí, a falta de interesse e de investimentos dos sucessivos governos, as transformações sociais e a influência dos meios de comunicação fizeram com que ela se tornasse uma instituição decadente. Em 2007, foi fechada para um amplo processo de reformas com o propósito de revitalizá-la. O presente trabalho procura demonstrar que a BMA só será capaz de recuperar o seu espaço com a realização de um projeto amplo, que contemple questões como os anseios e as expectativas dos usuários, a busca da integração entre a biblioteca e seu entorno e o resgate de seu papel como centro de difusão de cultura, de espaço de interação entre pessoas.

Palavras-chave: gestão da comunicação, biblioteca, centro de São Paulo, identidade, cultura, memória, pertencimento.
Abstract: Mário de Andrade Library owns the second biggest Brazilian hoard of books. Founded in 1926, reached its culmination between the 40's and 60's. Since then, the lack of interest and investments of the successive governments, the social changes and the influence of the means of communication lead it into a declining institution. In 2007, it was closed for an ample process of reforms in order to revitalize it. The present paper aims to demonstrate that Mário de Andrade Library will only be able to recover its place by accomplishing a wide project that contemplates aspects as the yearnings and expectations of the users, the integration of the library with its surroundings and the rescue of its role in culture dissemination, as well as a place for people to interact.

Keywords: management of the communication, library, center of São Paulo, identity, culture, memory, belonging.

A Mário de Andrade foi fundada em 1926 como a biblioteca municipal de São Paulo. Inicialmente instalada na Rua 7 de abril, foi transferida, em 1942, para o prédio onde funciona até hoje. São 22 andares, que abrigam 3,3 mi- 
de arte, entre outros. É o acervo mais completo sobre a cidade, especialmente da primeira metade do século XX, e o segundo maior do Brasil, atrás apenas da Biblioteca Nacional do Rio de Janeiro.

Entre as décadas de 1940 e 1960, viveu seu melhor momento. Bastante frequentada, tinha a seu favor a localização. O centro novo era considerado o epicentro cultural da cidade, abrigava também o prédio de Ciências Sociais da Universidade de São Paulo, o MAM e o MASP, as redações dos principais jornais, as rádios, os cinemas e teatros. Teve o privilégio de ter entre seus frequentadores nomes como Antônio Candido, Lygia Fagundes Telles, Fernando Henrique Cardoso e Ruth Cardoso, Fernando Torres e Fernanda Montenegro, Manoel Carlos, Ignácio de Loyola Brandão. Alguns deles fizeram parte do grupo conhecido como Adoradores da Estátua, que se reunia ao redor da imagem de Minerva, no saguão principal, para promover discussões ou simplesmente bater papo.

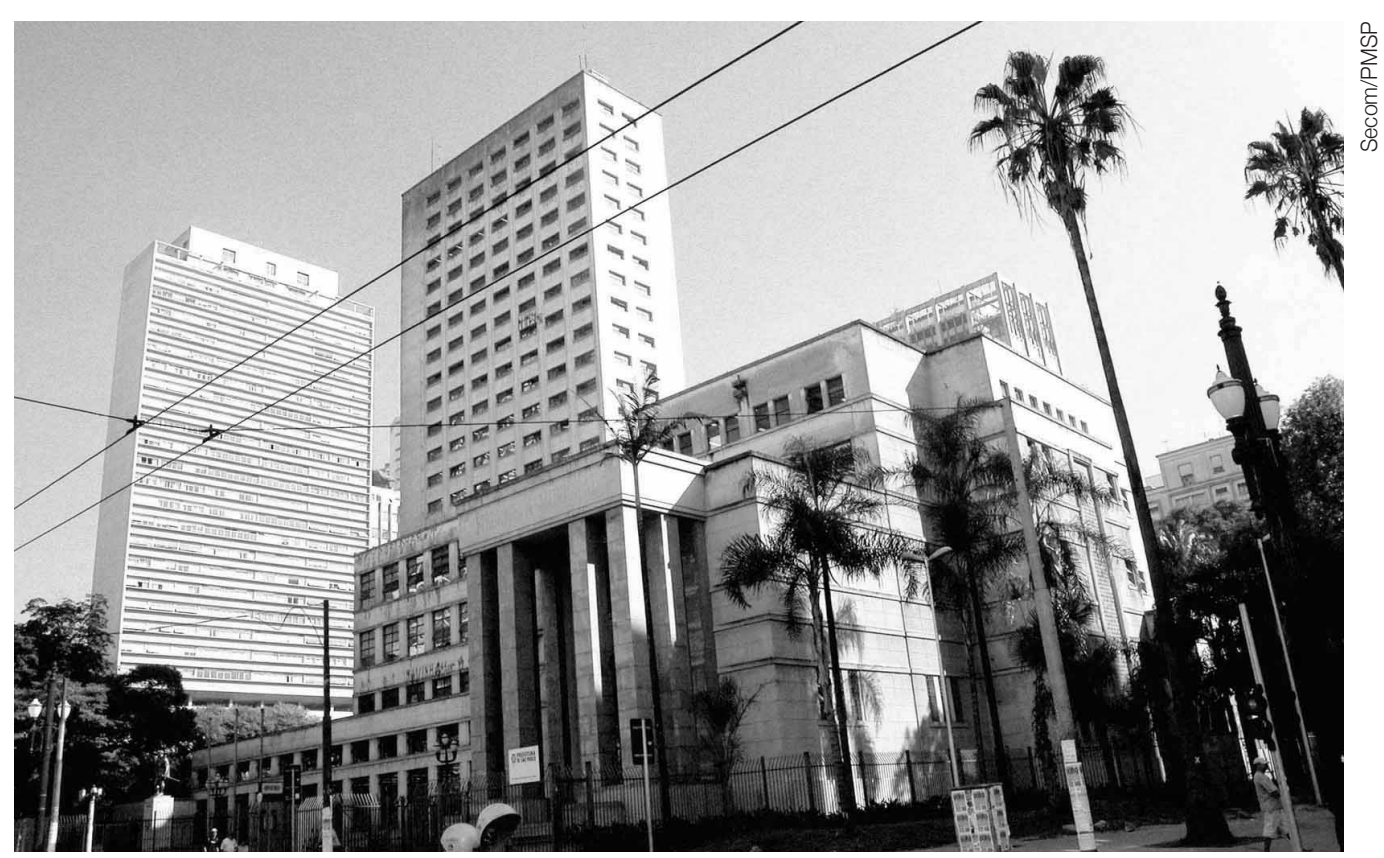

Com o segundo maior acervo do Brasil, a BMA foi fechada em 2007 para uma ampla reforma. A ideia é transformá-la em uma biblioteca voltada para pesquisadores.

Era, então, mais do que uma biblioteca convencional. Tratava-se de um polo cultural, ponto de encontro, local oportuno para conhecer pessoas e interagir com elas, trocar impressões.

Apesar de sua notória importância, desde meados dos anos 1970 a BMA sofre com a degradação das instalações, infestação, comprometimento e desatualização do acervo, redução significativa de investimentos e com o número cada vez menor de visitantes.

O presente artigo abordará o projeto de gestão da comunicação desenvolvido com o propósito de, ao mesmo tempo, buscar um entendimento quanto às transformações ocorridas ao longo dos últimos quarenta anos e propor caminhos para o resgate das características originais da instituição. 


\section{PENSAR UMA MÁRIO COMO MÁRIO}

A definição do problema de pesquisa levou em consideração dois fatores. Por um lado, as limitações estruturais e a falta de usuários. Por outro, o projeto de revitalização iniciado em 2007, que tem como ação prioritária a recuperação da edificação e do acervo, além da ampliação do espaço, com a anexação de um prédio cedido pelo Governo do Estado de São Paulo.

No entendimento do então diretor da instituição, a preocupação maior não deveria ser com a expansão do número de visitantes, e sim com sua qualificação. A intenção é atrair um público específico, formado por pesquisadores cujas áreas de estudos de alguma maneira se relacionam com os documentos ali guardados.

Tomando-se como referência as ideias do escritor responsável pela idealização da biblioteca, quando esteve à frente do Departamento de Cultura da municipalidade paulistana, tal perspectiva aparentemente confronta sua proposta original: a preocupação com os valores nacionais, com as tradições do povo brasileiro, com as memórias que fazem de um país nação. A chamada utopia de Mário de Andrade, que revela um sentido de construção participativo da identidade e:

Busca na cultura popular as expressões de um sensível coletivo, pois é nele que encontra a possibilidade de produção de cultura. Produção no seu sentido mais profundo, que abrange não só a capacidade, a habilidade de produzir, como - e talvez principalmente - a de imaginar o que produzir ${ }^{1}$.

Em suma, um modelo de biblioteca que privilegia determinado tipo de usuário, seja qual for, parece-nos inconcebível do ponto de vista do autor de Macunaima. É importante pensar nos pesquisadores, mas sem deixar de considerar também os atuais visitantes, alunos do Ensino Fundamental e Médio, professores, moradores da região central, trabalhadores etc.

Diante do exposto, elegemos como principal problema de pesquisa entender as razões para a redução do número de usuários. Afinal, por que potenciais frequentadores não a visitam? O que os teria levado a se afastar da BMA? E, de maneira complementar, identificar alternativas para que o processo de revitalização em curso possa retomar a essência da instituição. Como resgatar a Mário de Mário?

\section{A BIBLIOTECA E A CONTEMPORANEIDADE DO TREZENTOS-E-CINCOENTA}

As mesmas críticas lançadas aos modelos educacionais formais, tidos como ultrapassados, presos a métodos antiquados, incompatíveis com a vida contemporânea, talvez possam ser retomados com as bibliotecas. As formas tradicionais do serviço foram praticamente preservadas ao longo das décadas e a Mário de Andrade é um exemplo típico dessa estagnação. Exceto por tímidas incursões pela área de informática, quase tudo se mantém como tem sido desde o início

1. PIERONI: DENIPOLI (Org.). Saberes brasileiros: ensaios sobre identidades - Séc. XVI a XX. Rio de Janeiro: Bertrand Brasil, 2004. p. 181-182. 
comunicação \& educação • Ano XV • número 2 • maio/ago 2010

2. MARTÍN-BARBERO, Jesús. Heredando el futuro. Pensar la educación desde la comunicación (Herdando o futuro: pensar a educação a partir da comunicação). Revista Nómadas, s/d, p. 11

3. GOMEZ, G. Professores e meios de comunicação: desafios, estereótipos. Comunicação \& Educação, Brasil, v. 3, n 10, 2008. Disponível em: $<$ http://www.revistas. univerciencia.org/index. $\mathrm{php/comeduc/article/}$ view/4368>. Acesso em: 23 mar. 2010. do período de declínio: os arquivos de papel, a forma de organização dos livros, o acervo distante dos usuários, a falta de interlocução entre frequentadores e funcionários, a indisponibilidade de outros meios, de novos recursos.

Como aponta Jesús Martín-Barbero, a dificuldade de lidar com o novo, sobretudo as inovações tecnológicas e as transformações sociais decorrentes, tende a promover um choque de gerações. Como bem lembra o autor de $\mathrm{He}^{-}$ redando el futuro. Pensar la educación desde la comunicación, vivemos o momento de ruptura. É o tempo da "comunidade mundial", de múltiplas formas, modos. De imigrantes, migrantes e nativos. De novo e velho. De tempo real.

Un futuro que balbucean los relatos de ciencia-ficción en los que los jóvenes encuentran su experiencia de habitantes de un mundo cuya compleja heterogeneidad no se deja decir en 'las secuencias lineales que dictaba la palabra impresa' y que remite a un aprendizaje fundado menos en la dependencia de los adultos que en la propia exploración que los jóvenes habitantes del nuevo mundo tecnocultural hacen de la visión, la audición, el tacto o la velocidad ${ }^{2}$.

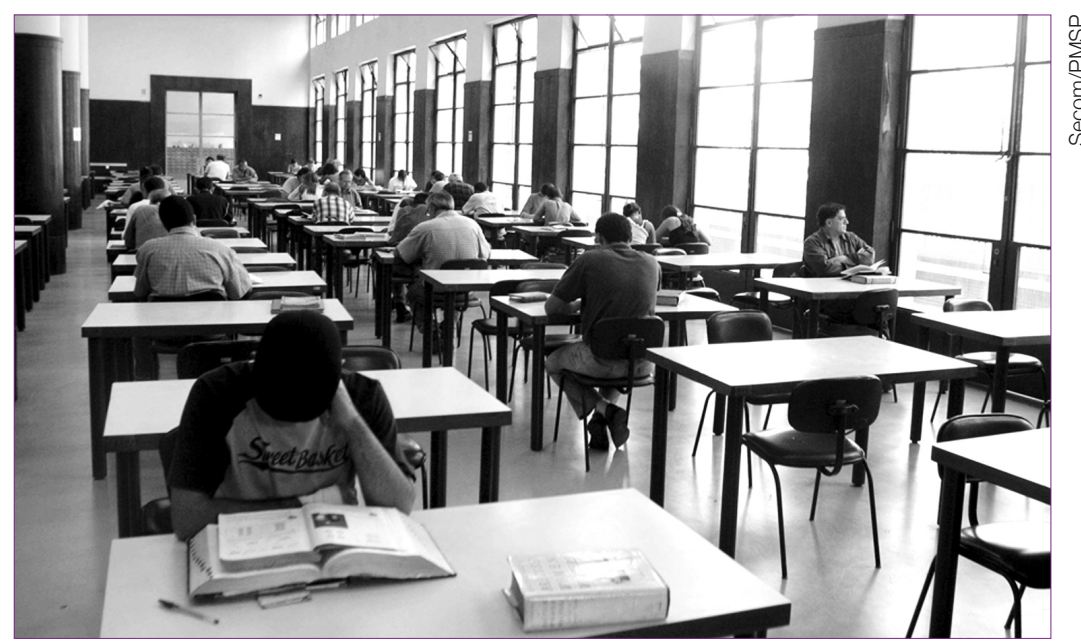

Ao longo das últimas quatro décadas, o número de frequentadores caiu drasticamente.

A manutenção de um modelo de biblioteca ultrapassado estaria entre os principais motivos.

Ainda nesta perspectiva, Guillermo Orozco alerta sobre os desafios impostos a partir da criação, aperfeiçoamento e disseminação dos meios de comunicação de massa. Sua influência passa por transformações que estariam contribuindo para a criação do que ele mesmo chama de novos sistemas linguísticos do futuro, que se diferenciam dos anteriores a partir da lógica de suas articulações ${ }^{3}$. Em última instância, o que é produzido, o conteúdo efetivamente e as novas formas de construção e transmissão de mensagens associam códigos de diferentes naturezas (oral, escrita, visual e audiovisual), com técnicas/tecnologias que permitem mobilidade e rapidez.

Ao lado da degradação do centro, das instalações e dos serviços do equipamento cultural, bem como da influência dos meios de comunicação, as transformações do comportamento social podem ter participação significativa não apenas na redução do número de frequentadores, mas também no desaparecimento dessa função de ponto de encontro da instituição. Há tempos ela 
já não é o local aonde as pessoas vão para se conhecer, para firmar relações que sejam menos esporádicas e mais duradouras, para interagirem.

Em síntese, partimos do entendimento de que a redução do número de usuários da BMA seria consequência basicamente:

1. do aumento do número de bibliotecas públicas e particulares;

2. da disponibilização de outras formas de lazer e entretenimento em quantidade e a preços acessíveis;

3. do barateamento de produtos (como o livro) e serviços com o desenvolvimento técnico/tecnológico;

4. do nascimento de uma sociedade ligada à imagem com a ascensão dos Meios de Comunicação de Massa (MCM);

5. da manutenção de uma biblioteca presa a modelos ultrapassados;

6. da falta de uma área de comunicação interna;

7. da deterioração da qualidade do serviço; e

8. da transformação da cidade e do comportamento social.

Em contrapartida, as expectativas dos potenciais usuários podem apontar para:

1. a disponibilização de uma gama maior de produtos e serviços pela internet;

2. a possibilidade de assumir papel de partícipe na construção desta biblioteca;

3. a existência de um espaço que não se restrinja ao serviço de consulta e empréstimos de livros; e

4. a viabilidade de um espaço que dê vozes às diferentes vozes.

De alguma maneira a biblioteca deve corresponder às novas demandas sociais. Repensar a instituição com base não só em uma época em que as barreiras temporais e espaciais foram rompidas, mas também a partir de uma nova perspectiva, que leve em consideração os aspectos multifacetados da sociedade, de um e de todos. Ou melhor, a exemplo de Mário de Andrade, uma biblioteca que possa atender um novo usuário, que ao mesmo tempo é um e trezentos-e-cincoenta ${ }^{4}$.

\section{DESAFIOS MARIDIANOS DE UM GESTOR}

Um dos desafios estabelecidos por este projeto foi a busca por um modelo de comunicação à margem da forma de instrumentalização recorrente, que tende ao simplismo, ao tratamento parcial e a soluções que, muitas vezes, apresentam moderados resultados imediatos, mas sem os impactos possíveis de longo prazo.

O trabalho pretendia tomar como referência a discussão promovida por Luiz Roberto Alves em torno do papel do profissional de gestão da comunicação. A missão de encontrar caminhos para os problemas específicos da instituição, sem deixar de ignorar as feições das deficiências da sociedade atual, de maneira mais ampla, e da comunicação.

A incapacidade observada hoje de responder às demandas reais da sociedade, quando os esforços se voltam quase exclusivamente para o que o

4. ANDRADE, Mário. Poesia completa. Edição crítica de Dilea Zanotto Manfio. São Paulo: Villa Rica Editora, 1993. 
comunicação \& educação • Ano XV • número 2 • maio/ago 2010

autor considera a linha de estudo associada à mercadotecnia, em detrimento dos estudos humanistas e sociais ${ }^{5}$; a carência de ações comunicativas que se pautem na cidadania e no neoliberalismo; o falso discurso liberal pós-moderno, que insinua a existência de uma sociedade do conhecimento, com vocação para a resolução de problemas; a apropriação inadequada dos conceitos de mediação e de hibridismo (a primeira como forma de indução à brecha, ao consumo e ao prazer; e a segunda como visão estereotipada das inter-relações entre culturas e classes). Transformar tais problemas em oportunidades é dever do gestor da comunicação, bem como se livrar dos vícios comuns à maioria dos profissionais da área, que saem das fileiras da universidade já com um modelo de sistematização incorporado.

E são as palavras de Alves que melhor traduzem os princípios que devem nortear as ações deste profissional:

[...] cabe aos educadores-pesquisadores de comunicação e cultura a melhor descrição dessa sociedade, a sensibilização diante dos novos modos de exercício do poder e seus modelos retóricos, o fortalecimento da atitude de ouvir as dificuldades narrativas e, ato contínuo, acompanhar experiências democratizadoras incidentes sobre os meios e os processos comunicacionais e culturais ${ }^{6}$.

O objetivo foi acrescer esta perspectiva ao estudo realizado para a BMA: a visão mais ampla a respeito da comunicação, da sociedade, do objeto de estudo; o olhar mais humanizado, pela democratização; a abordagem que permita a consolidação de uma proposta de biblioteca, na medida do possível, ao sabor do seu idealizador, despida de falsas pretensões; uma Mário de Andrade para Mário de Andrade.

\section{DAR VOZES ÀS VOZES}

Além do levantamento e análise bibliográficos, a entrevista foi o principal instrumento utilizado para atingir os objetivos específicos da pesquisa. No que tange ao formato, adotou-se a entrevista semiaberta. O diálogo foi intermediado por um roteiro e questões eram incluídas de acordo com o direcionamento da pesquisa. Em relação ao meio utilizado para o levantamento dos dados, variou conforme a disposição dos potenciais entrevistados. Em geral, as entrevistas foram presenciais, com o auxílio de um gravador e anotações manuscritas. Em duas situações, elas foram realizadas por e-mail. Houve duas ainda feitas por telefone.

Ao todo, quase seis horas de conversa, com onze pessoas e mais de setenta páginas de transcrições. Três grupos distintos foram considerados nesta etapa dos trabalhos. Parâmetros de caracterização e temas para abordagem dirigida

5. ALVES, Luiz Roberto. Planejando os projetos de comunicação. In: BAC CEGA, Maria Aparecida (Org.). Gestão de processos comunicacionais. São Paulo: Atlas, 2002. p. 136.

6. Ibid., p. 141 foram desenvolvidos para cada um. São eles:

a) ex-usuários e potenciais usuários - um pesquisador, que utilizou os arquivos da instituição para desenvolver estudos, além de uma pessoa que mora e duas que trabalham na região central, mais especificamente nas proximidades da Mário de Andrade. Os diálogos basicamente giraram em torno de três temáticas: (1) Visão sobre bibliotecas, em especial da 
Desvario de comunicação possível para a biblioteca da pauliceia - Rogério P. de Andrade

Mário de Andrade; (2) Opinião sobre o centro da cidade; (3) Modelo de biblioteca ideal.

b) empreendedores - os donos da Livraria da Vila, da Livraria Cultura e do Grupo Mancini. Os dois primeiros, não apenas pelo tipo de negócio que administram, mas também pelas características de suas lojas: ambiente aconchegante e a disponibilização de serviços como cursos e palestras. $\mathrm{O}$ último pelo projeto de revitalização realizado na Rua Avanhandava, que é próxima à BMA, e pela aposta em projetos culturais como a galeria Caligraphia. Os assuntos que conduziram as conversas foram: (1) Visão sobre bibliotecas, em especial da Mário de Andrade; (2) Opinião quanto aos motivos pelo desinteresse do público pelas bibliotecas; (3) Opinião sobre o centro da cidade; (4) Sugestão para a revitalização da Mário de Andrade; e (5) Opinião sobre parcerias com empresas privadas ou do terceiro setor.

c) especialistas - o jornalista Gilberto Dimenstein, o coordenador dos Núcleos de Ação Educativa e ex-presidente da Imprensa Oficial do Estado de São Paulo, Sérgio Kobayashi, o diretor do Centro Cultural São Paulo, Martin Grossman, e o superintendente do Museu da Língua Portuguesa, Antonio Carlos de Moraes Sartini. Os temas tratados foram essencialmente os mesmos abordados junto aos empreendedores.

\section{RESULTADOS}

O primeiro detalhe a ser destacado é o senso comum com relação aos pontos negativos da região em que está localizada a Biblioteca Mário de Andrade. O mais citado é a insegurança. Todos os representantes da categoria ex e potenciais frequentadores mencionaram o tema como fator limitador de uma possível visita à biblioteca. Especialmente no período noturno, quando a maioria dos estabelecimentos comerciais está fechada, as ruas ficam escuras e aumenta o tráfego de moradores de rua. Outros problemas citados, em uma escala menor de intensidade, mas ainda com certa constância, foram a limpeza e a má conservação geral (prédios, ruas, jardins etc).

Se, por um lado, o fator localização pesa contra a BMA, por outro favorece. O fácil acesso e a diversificação dos serviços foram mencionados como pontos positivos do centro da cidade por três dos quatro ouvidos.

Das 11 pessoas que participaram das entrevistas, apenas uma nunca havia entrado na Mário de Andrade. Quase todos não a visitam há anos e, de maneira geral, aqueles que opinaram a respeito da imagem que preservam dela, retrataram uma lugar com problemas estruturais, mal iluminado, desconfortável, cujo atendimento deixava a desejar.

Mas a visão negativa não é particular à BMA. O problema seria das bibliotecas em geral, sobretudo as mantidas pelo governo. Falta de investimentos e desinteresse das sucessivas administrações, a burocracia, o despreparo de gestores e funcionários, os acervos desatualizados, o mau estado de conservação de mobiliário e dos livros, a falta de informatização do catálogo, são referências que contribuem para a consolidação desta percepção. 
comunicação \& educação • Ano XV • número 2 • maio/ago 2010

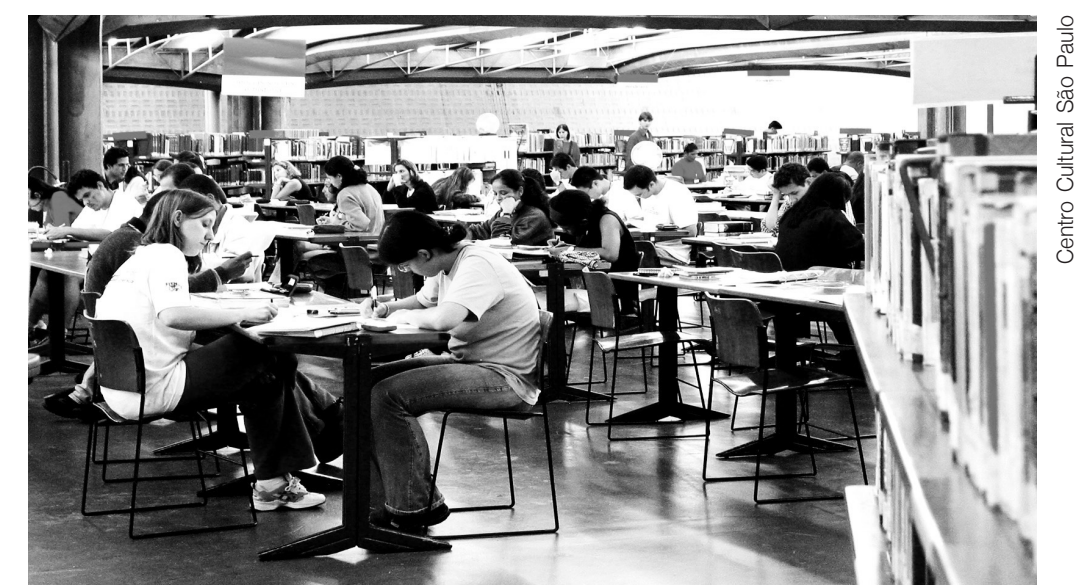

Alguns caminhos, como o trilhado pelo Centro Cultural de São Paulo (CCSP), podem ser adaptados à Mário de Andrade: aproximar o acervo dos usuários, associá-lo às novas tecnologias e criar um ambiente que estimule a inter-relação entre os frequentadores.

A internet é considerada o principal fator de distanciamento do público. Não é a primeira opção de todos, mas da maioria. A rapidez, comodidade, praticidade e facilidade são os aspectos que favorecem a rede de computadores.

Dentre as transformações que poderiam ser realizadas com o propósito de torná-la mais frequentada, basicamente cinco foram citadas: (1) a diversificação dos serviços - introdução de cursos e palestras, espetáculos de música, teatro e dança; (2) a informatização - disponibilização de computadores, de maneira que haja interação entre livros e equipamentos de informática, banco de dados das obras e criação de acervos virtuais; (3) a atualização do acervo - obras atuais, de assuntos diversos, que interessem ao público leitor e, de maneira mais direta, ao jovem; (4) implantação de estratégia de divulgação - atuar nos hotéis, empresas e demais estabelecimentos da região, junto a outros equipamentos culturais, e realizar parcerias para tornar a ação mais bem-sucedida; e (5) o conforto instalação de café, poltronas e cadeiras mais confortáveis e música ambiente.

No que diz respeito ao estabelecimento de parcerias com organizações não governamentais para a obtenção de recursos e a transferência da administração do equipamento cultural, dos oito que foram convidados a opinar, dois se mostraram contrários à ideia. Os demais viram como uma possibilidade de tornar os processos mais ágeis e de facilitar a contratação de mão de obra qualificada.

\section{UM PROJETO DE GESTÃO}

Estabelecemos cinco eixos principais, interligados entre si, para o desenvolvimento do projeto de intervenção. O primeiro, apesar de se distanciar das funções estritas do gestor de comunicação, diz respeito ao modelo ideal de administração. Por conta das limitações existentes no formato estatal, destacadas, inclusive, de parte dos entrevistados, o entendimento é de que a melhor alternativa seria a transferência para organizações do terceiro setor. Dessa maneira, seria possível aumentar a flexibilidade administrativa e a expectativa por maiores recursos. 


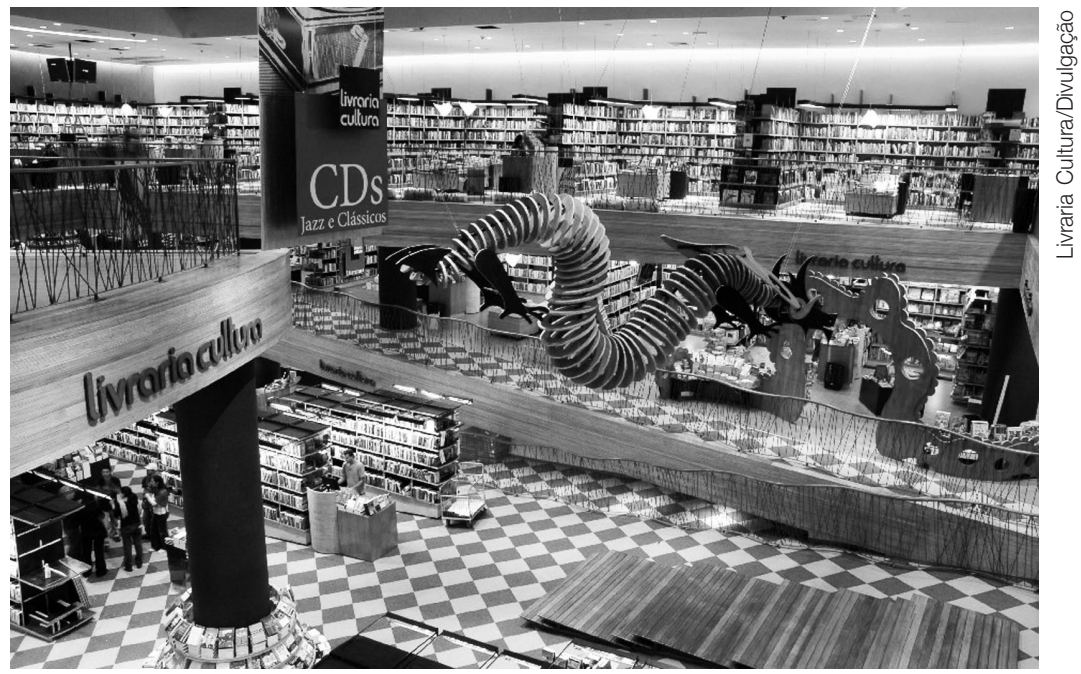

A exemplo do que se verifica nas livrarias, criar espaços aconchegantes, com poltronas, pufes, iluminação agradável e café seria um meio de não apenas atrair o público, mas também de mantê-lo na biblioteca.

O segundo eixo é resultado do entendimento de que a Biblioteca precisa repensar o seu espaço, criar um ambiente mais acolhedor, no qual as pessoas possam se sentir mais próximas umas das outras, que forneça condições para que elas sejam capazes de interagir entre si e com a própria instituição.

Para tanto, seria necessária a adequação de determinados locais, como saguão onde se localiza a estátua de Minerva e a sala anexa, cujas portas dão acesso à Praça Dom José Gaspar. Sugerimos que nestes ambientes sejam incorporadas estantes de livros, poltronas e sofás, pufes e tapetes, luminárias, pequenos móveis de apoio e amplas mesas com livros empilhados. Tanto nas estantes quanto no restante do mobiliário utilizado para armazenar as obras não haveria nenhum tipo de ordem ou organização.

Complementam esta proposta a instalação de um café e de uma loja de suvenires e a distribuição de computadores nos diferentes ambientes da instituição, de maneira a promover a interação entre equipamentos de informática e o acervo convencional da biblioteca.

O terceiro eixo guarda relação com a intenção de promover a aproximação da Mário de Andrade com o seu entorno. Buscar uma convivência mais próxima dos moradores, dos trabalhadores e dos estabelecimentos que estão localizados na região.

A exploração principalmente da Praça Dom José Gaspar como extensão da Mário de Andrade, com a promoção de eventos, como shows e cursos ao ar livre, a manutenção da limpeza e o estabelecimento de laços com os demais ocupantes da região é maneira de torná-la viva, de aproximá-la do público, de romper estas barreiras.

O quarto eixo se concentra nas ferramentas de comunicação dirigidas. Sugerimos a criação de uma área responsável pela gestão destas atividades e a necessidade de utilizar a internet como aliada no processo de revitalização. O sítio da BMA seria readequado, com especial atenção à ampliação e diversificação do 
comunicação \& educação • Ano XV • número 2 • maio/ago 2010

conteúdo, e os funcionários treinados com foco em atendimento e capitação dos anseios dos visitantes.

Por fim, o quinto eixo aborda a necessidade de diversificação das atividades. Sem ignorar a verdadeira finalidade da biblioteca, propomos a realização de uma série de ações ligadas à literatura, ao teatro, à música e às artes plásticas, entre outras. A ideia é planejar e oferecer uma gama maior não só de cursos, mas também de eventos como exposições, espetáculos teatrais, de música e dança, promoção de feiras de livros ou de antiguidades etc. Além disso, determinados espaços poderiam ser disponibilizados para os interessados em fazer locações para atividades como lançamentos de livros e vernissage.

\section{CONCLUSÃO}

A recuperação da maior biblioteca de São Paulo só poderá ser efetiva se houver a compreensão de que conservar a memória é menos um ato de guarda e mais um gesto de revelação. É preciso mostrar, fazer com que as pessoas vejam; observar o que as pessoas veem; ouvir e tentar compreender o que as pessoas querem ver.

Cabe ainda admitir que a biblioteca vai além do espaço físico. Ela está no entorno, nos hábitos e comportamentos sociais, na busca de soluções que permitam a transposição das conhecidas barreiras do acesso à cultura.

Neste sentido, faz-se necessário conceber um projeto de biblioteca moderno, que vá ao encontro da perspectiva de fazer da Mário de Andrade de amanhã a Mário de Andrade que Mário de Andrade idealizou.

\section{REFERÊNCIAS BIBLIOGRÁFICAS}

ALVES, Luiz Roberto. Planejando os projetos de comunicação. In: BACCEGA, Maria Aparecida (Org.). Gestão de processos comunicacionais. São Paulo: Atlas, 2002.

ANDRADE, Mário. Poesia completa. Edição crítica de Dilea Zanotto Manfio. São Paulo: Villa Rica Editora, 1993.

MARTÍN-BARBERO, Jesús. Heredando el futuro. Pensar la educación desde la comunicación (Herdando o futuro: pensar a educação a partir da comunicação). Revista Nómadas. s/d.

PIERONI; DENIPOLI (Org.). Saberes brasileiros: ensaios sobre identidades Séc. XVI a XX. Rio de Janeiro: Bertrand Brasil, 2004.

\section{Endereços eletrônicos}

GOMEZ, G. Professores e meios de comunicação: desafios, estereótipos. Comunicação \&Educação, Brasil,v. 3, n. 10, 2008. Disponível em: <http:/ /www.revistas.univerciencia. org/index.php/comeduc/article/view/4368>. Acesso em: 23 mar. 2010 